\title{
XPS analysis with external bias: a simple method for probing differential charging
}

\author{
Gulay Ertas and Sefik Suzer* \\ Bilkent University, Chemistry Department, 06800 Ankara, Turkey \\ Received 7 November 2003; Revised 1 March 2004; Accepted 1 March 2004
}

\begin{abstract}
The XPS spectra of thermally grown oxide layers on $\mathrm{Si}, \mathrm{Al}, \mathrm{W}$ and $\mathrm{Hf}$ substrates have been recorded while the samples were subjected to external d.c. voltage bias. The bias induces additional shifts in the measured binding energy differences between the XPS peaks of the oxide and that of the metal substrate in Si and Al (as probed both in the $2 \mathrm{p}$ and the KLL Auger regions), but not in $\mathrm{W}$ and $\mathrm{Hf}$ (as probed in the $4 \mathrm{f}$ region). These bias induced shifts are attributed to differential charging between the oxide layer and the substrate, which in turn is postulated to be related to the capacitance and inversely to the dielectric constant of the oxide layer. Accordingly, silicon dioxide with the smallest dielectric constant undergoes the largest differential charging, aluminium oxide is in the middle and no appreciable charging can be induced in the high- $k$ tungsten and hafnium oxides, all of which are $\sim 6 \mathrm{~nm}$ thick. Copyright $\subset 2004$ John Wiley \& Sons, Ltd.
\end{abstract}

KEYWORDS: differential charging; external biasing; metal oxides; dielectric constant

\section{INTRODUCTION}

Thin oxides (1-10 nm) of various metals are of great interest in many aspects of science and engineering applications and XPS is ideally suited for the characterization of these systems. Almost all of the information derivable from XPS relies on the measured binding energy differences (socalled chemical shift). Chemical shift is usually analysed in terms of initial- and final-state effects but because XPS measures the emitted electrons a finite (albeit small) current unavoidably develops within the sample that can contribute to the measured binding energy difference as a result of differential charging. ${ }^{1-6}$ Although several elegant techniques have been developed to minimize the differential charging, complete elimination is not possible. ${ }^{7}$ Utilization of the surface charging for deriving important chemical, physical and structural information about surface structures also has been reported. ${ }^{8-17}$ Detection of the presence and/or an estimate of the extent of differential charging within the system analysed is always desirable. We have reported recently that application of a small $(1-20 \mathrm{~V})$ external bias while recording the XPS spectrum is a simple and effective method to detect and/or verify the presence of differential charging. ${ }^{18}$ We now extend it to include aluminium and two high- $k$ systems (hafnium and tungsten) and relate the extent of differential charging to the capacitance of these thin oxide layers.

It has long been established that the measured binding energy difference in $\mathrm{Si} 2 \mathrm{p}$ level between the oxide $\left(\mathrm{Si}^{4+}\right)$

*Correspondence to: Sefik Suzer, Bilkent University, Chemistry

Department, 06800 Ankara, Turkey.

E-mail: suzer@fen.bilkent.edu.tr

Contract/grant sponsor: Turkish Academy of Sciences. and the silicon substrate $\left(\mathrm{Si}^{0}\right)$ increases from 3.2 to $\sim 5.5 \mathrm{eV}$ as the thickness of the oxide layer increases to $10 \mathrm{~nm}$. This increase has been the subject of a lengthy debate among both experimentalists and theoreticians. ${ }^{19-29}$ In the previous work mentioned above ${ }^{18}$ we applied a small external bias to demonstrate the existence of differential charging all the way down to oxide layers of $1 \mathrm{~nm}$ thickness in $\mathrm{SiO}_{2} / \mathrm{Si}$, in agreement with Iwata and Ishizaka ${ }^{30}$ but contradicting the earlier verdict that charging starts to set in only after $3 \mathrm{~nm} \cdot{ }^{31-35}$ Similar observations also have been reported for the $\mathrm{Al}_{2} \mathrm{O}_{3} / \mathrm{Al}$ system. ${ }^{30,36-38}$ It is also well established that charging is a serious issue for XPS analysis of high- $k$ oxide systems, which have attracted interest recently for their potential use as gate materials. ${ }^{39,40}$

Application of an external bias in XPS was first reported by Dickinson et al. ${ }^{41}$ and Johansson et al. ${ }^{42}$ but it has not been utilized extensively. Recently, Howercraft and Sherwood applied it to identify the chemical differences in oxide films on an aluminium alloy. ${ }^{43}$ We had demonstrated that these arise as a result of partial neutralization by stray electrons within the vacuum system, and applying a positive bias attracts more of these stray electrons to the sample, causing a more effective neutralization and hence reducing the extent of differential charging and negative bias acting in the opposite direction. ${ }^{18}$ We later incorporated a filament to supply additional stray electrons within the vacuum system, achieving more neutralization and decreasing the differential charging further down. ${ }^{44}$

\section{EXPERIMENTAL}

Experimental procedure is very simple and involves recording the XPS spectrum while applying an external bias to the 


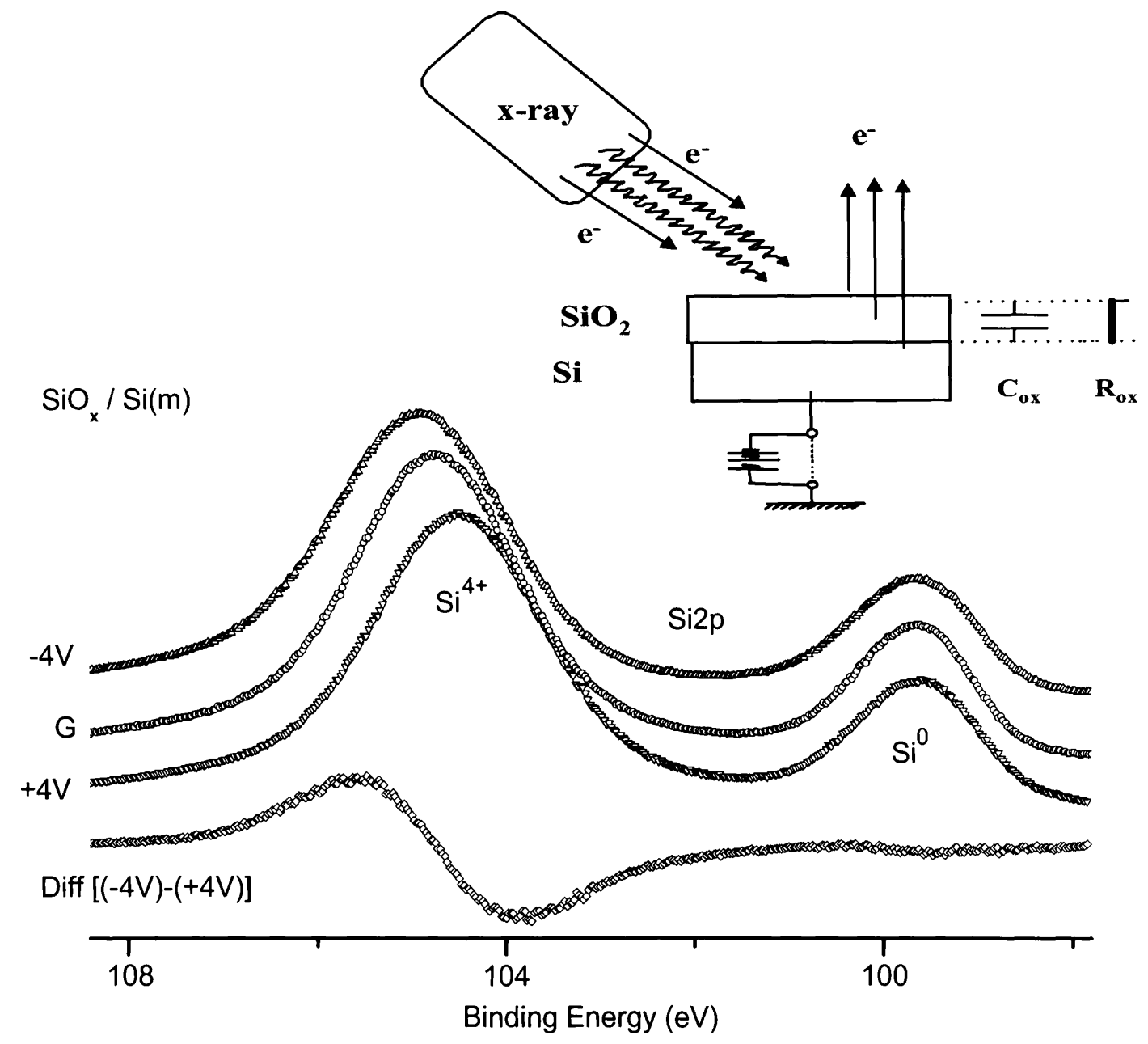

Figure 1. The Si $2 p$ region of the XPS spectrum of a silicon sample containing $\sim 6 \mathrm{~nm}$ oxide layer recorded when the sample was grounded and under $-4 \mathrm{~V}$ and $+4 \mathrm{~V}$ external bias. The difference spectrum, obtained by subtracting the spectrum recorded under positive bias from that under negative bias, is also shown. The inset shows schematically the experimental set-up as well as an equivalent circuit of the oxide layer.

sample. The oxide layers are grown thermally on cleaned metal substrates in air. A Kratos ES300 electron spectrometer with $\mathrm{Mg} \mathrm{K} \alpha$ x-rays (non-monochromatic) is used for XPS measurements. The sample accepts $x$-rays at $45^{\circ}$ and emits photoelectrons at $90^{\circ}$ with respect to its surface plane. The sample also can be rotated to decrease the emission angle (electron take-off angle) in order to enhance surface sensitivity and also to estimate the thickness of the oxide layer. ${ }^{45}$ Throughout this study no additional electrons were introduced via the external filament.

\section{RESULTS AND DISCUSSION}

As depicted in Fig. 1 for the silicon substrate containing $\sim 6 \mathrm{~nm}$ oxide, the measured Si $2 p$ binding energy difference between $\mathrm{Si}^{4+}$ and $\mathrm{Si}^{0}$ is $5.01 \mathrm{eV}$ when the sample is grounded and increases to $5.22 \mathrm{eV}$ when $-4 \mathrm{~V}$ is applied, but it decreases to $4.81 \mathrm{eV}$ with application of a $+4 \mathrm{~V}$ bias (Table 1 ). A smaller but significant $\mathrm{Al} 2 \mathrm{p}$ binding energy difference also exists between the oxide and the metal substrate in the case of aluminium (as shown in Fig. 2 and given in Table 1), but no measurable $4 \mathrm{f}$ binding energy difference can be observed in the case of tungsten (Fig. 3) and hafnium
Table 1. The Si $2 p$ and Al $2 p$ binding energies (in $\mathrm{eV}$ ) of silicon and aluminium substrates containing $\sim 6 \mathrm{~nm}$ native oxide as determined by XPS with and without the application of an external bias (differences in derived Auger parameters $\alpha^{46}$ are also included)

\begin{tabular}{lcccc}
\hline & \multicolumn{3}{c}{$\Delta \mathrm{BE}(\mathrm{eV})$} & $\Delta \alpha(\mathrm{eV})$ \\
\hline & $\mathrm{Si}^{0}$ & $\mathrm{Si}^{4+}$ & & \\
\hline Grounded & $99.50^{\mathrm{a}}$ & 104.51 & 5.01 & 3.92 \\
$+4 \mathrm{~V}$ & 99.50 & 104.31 & 4.81 & 3.93 \\
$-4 \mathrm{~V}$ & 99.50 & 104.72 & 5.22 & 3.91 \\
\hline & $\mathrm{Al}^{0}$ & $\mathrm{Al}^{3+}$ & & \\
\hline Grounded & $72.85^{\mathrm{a}}$ & 75.61 & 2.76 & 4.51 \\
$+4 \mathrm{~V}$ & 72.85 & 75.50 & 2.65 & 4.51 \\
$-4 \mathrm{~V}$ & 72.85 & 75.71 & 2.86 & 4.50 \\
\hline
\end{tabular}

${ }^{a}$ Taken as the reference.

(not shown). It is also worth mentioning that, in the case of silicon and aluminium, the Auger parameter ${ }^{46}$ (Table 1) is not influenced by the bias, reinforcing our argument that 


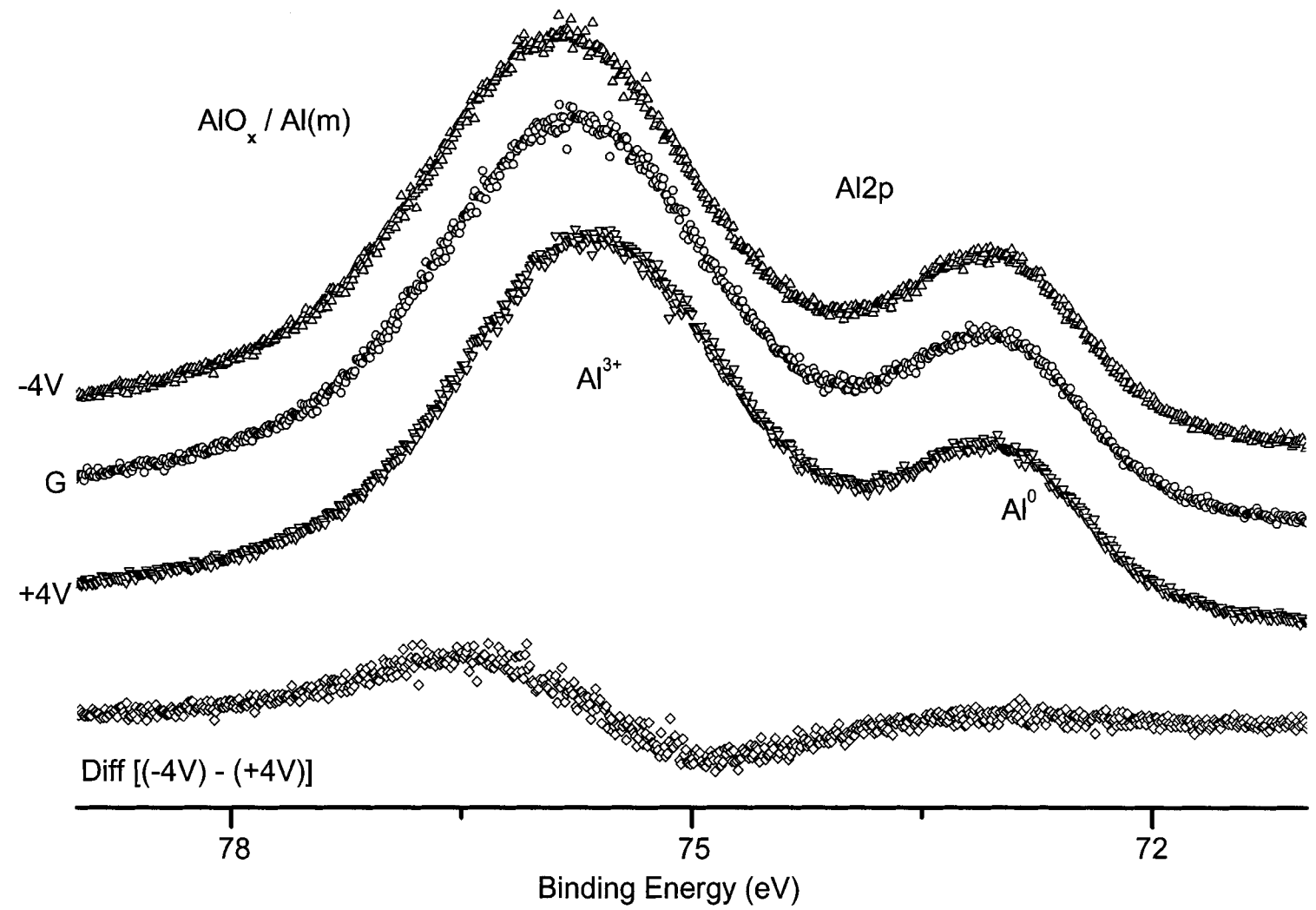

Figure 2. The Al $2 p$ region of the XPS spectrum of an aluminium sample containing a comparable oxide layer to that of silicon shown in Fig. 1.

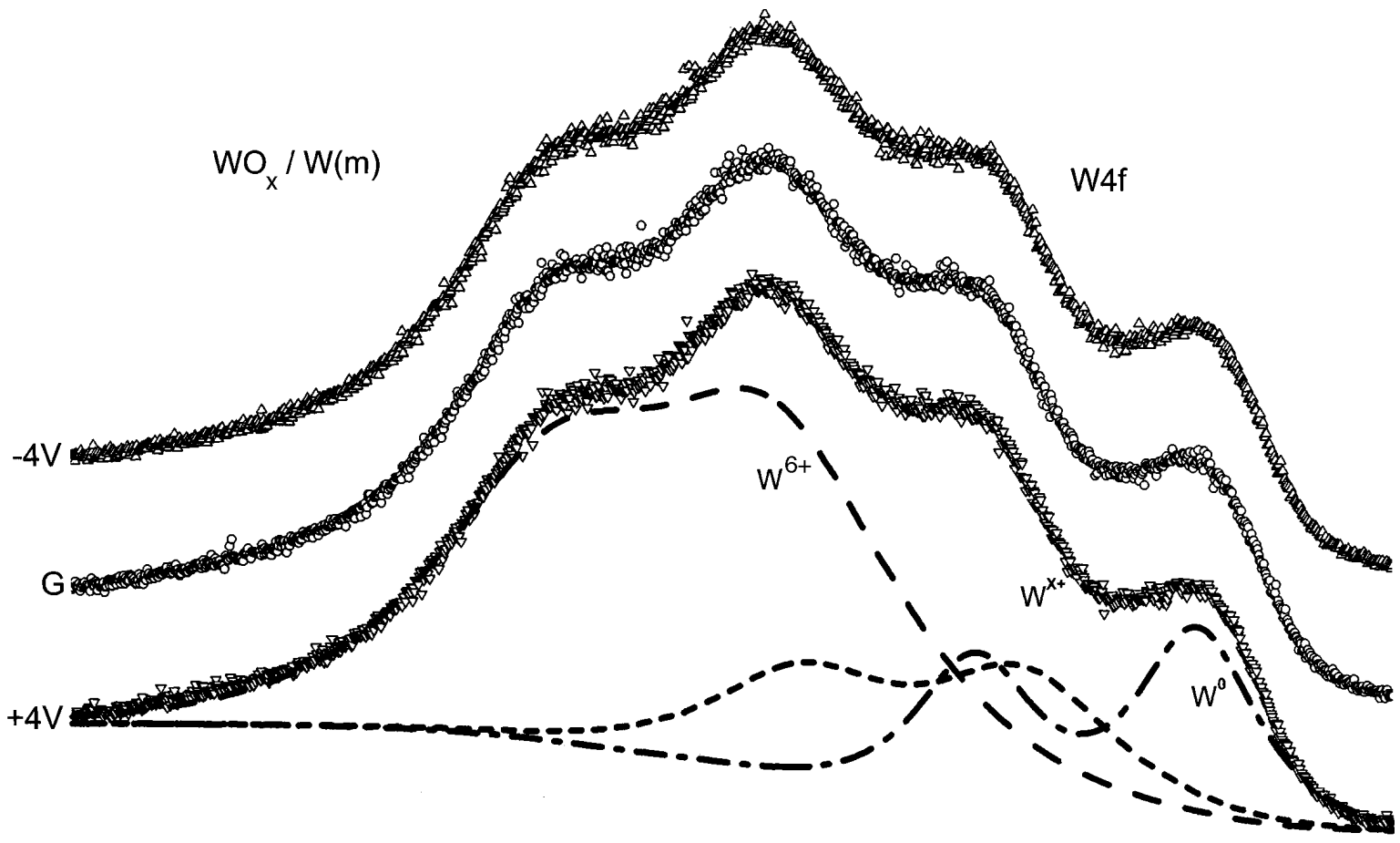

Diff $[(-4 V)-(+4 V)]$ W W

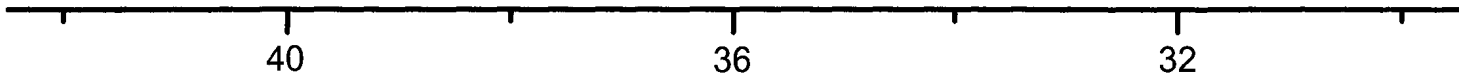

Binding Energy (eV)

Figure 3. The $\mathrm{W} 4 \mathrm{f}$ region of the XPS spectrum of a tungsten sample containing a comparable oxide layer to that of silicon shown in Fig. 1. In addition to the metal and the full oxide peaks, suboxide peaks are also present. 
the bias-induced shifts have physical rather than chemical origin. ${ }^{44}$ Accordingly, the differential charging is large for the thin $(1-10 \mathrm{~nm})$ oxide-on-metals of silicon, medium for aluminium and negligible for hafnium and tungsten as determined by XPS.

Using a similar approach to that used in Ref. 17, we can try to correlate the observed extent of charging for the same material as a function of its thickness or for different materials with comparable thicknesses to their resistance and capacitance, as shown schematically in the inset of Fig. 1. In Fig. 4(a) the measured bias-induced binding energy difference under a negative and positive external $4 \mathrm{~V}$ bias is plotted as a function of the oxide thickness of the silicon oxide layer. This saturation behaviour has long been reported and successfully modelled. ${ }^{29,30,33}$ We can only declare that our findings are in complete agreement with those reported.

It is the correlation of the extent of charging of the different oxides with comparable thicknesses that we are trying to shed light on. According to the simple equivalent circuit model, charging (more specifically differential charging) can be related to both the resistance and/or the capacitance of the sample (the oxide layer). The bulk resistivities of $\mathrm{SiO}_{2}$ and $\mathrm{Al}_{2} \mathrm{O}_{3}$ are $10^{16}$ and $10^{11}(\Omega \cdot \mathrm{m})$, respectively, and are so drastically different to warrant a simple correlation with our observations. ${ }^{47}$ Hence, we now postulate that the extent of charging can be correlated to the capacitance of the oxide

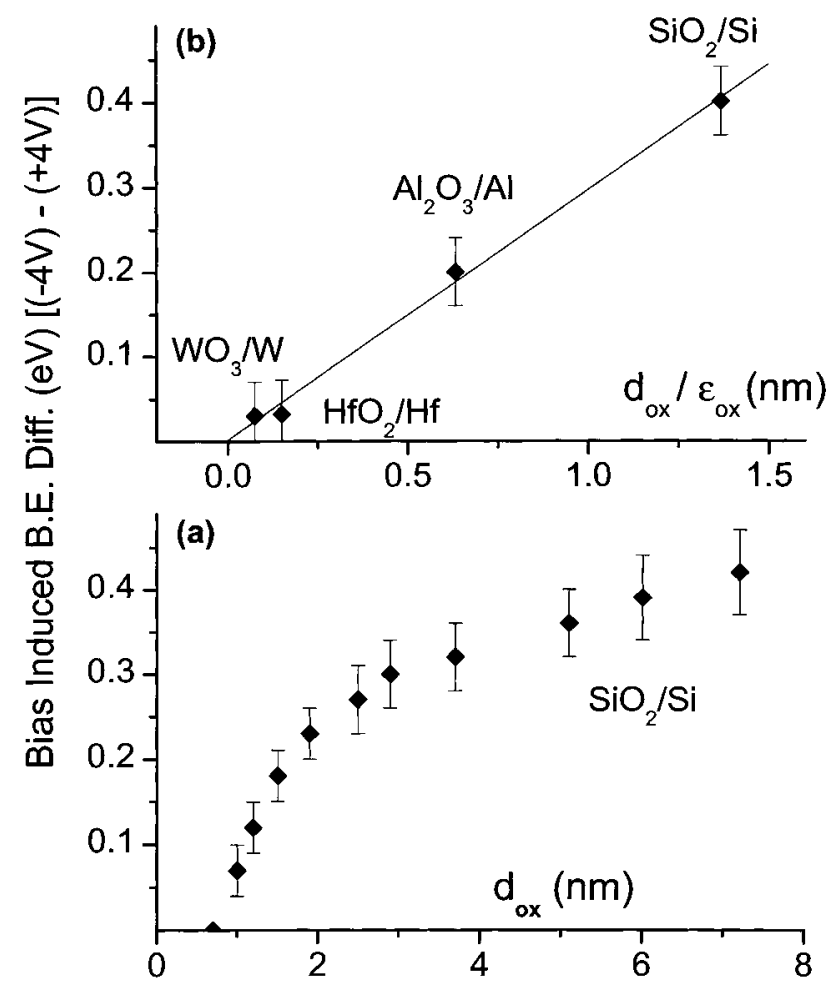

Figure 4. (a) The measured bias-induced binding energy difference between the oxide layer and the silicon substrate plotted against the thickness of the oxide layer. (b) The measured bias-induced binding energy difference between the ( $\sim \mathrm{nm}$ thick) oxide layers and the metal substrates scaled against the reciprocal of the bulk dielectric constants of the oxides. layer, which can induce a potential difference

$$
\Delta V_{\mathrm{ox}}=Q / C_{\mathrm{ox}}=Q\left(d_{\mathrm{ox}} / \varepsilon_{\mathrm{ox}}\right)
$$

where $Q$ is the total charge accumulated, $d_{\mathrm{ox}}$ is the thickness and $\varepsilon_{\mathrm{ox}}$ is the dielectric constant of the oxide layer. Because application of the bias effectively causes partial neutralization, we expect, to a first-order approximation, the bias-induced shift also to be proportional to $\left(d_{\mathrm{ox}} / \varepsilon_{\mathrm{ox}}\right)$. Such a simple correlation seems to be valid, as shown in Fig. 4(b) where the measured bias-induced binding energy shift is plotted against the thickness of the oxide layer divided by the bulk dielectric constant. The thickness of the oxide layer is determined from the angular dependence of the XPS intensity ratio of the oxide to the substrate peaks. ${ }^{45}$

The surface potential of the oxide is influenced by a variety of charge sources, some of which are related to the particular XPS spectrometer in use and the photoelectron emission process and others to the sample under investigation. In addition, many of these parameters are also influenced by the external bias introduced. Hence, the simple correlation postulated here may be fortuitous and needs more data and modelling. However, application of an external bias is a simple but effective method of checking/verifying the existence of differential charging in these thin oxide/metal systems.

\section{Acknowledgement}

This work is partially supported by TUBA (Turkish Academy of Sciences).

\section{REFERENCES}

1. Hnatowich DJ, Hudis J, Perlman ML, Ragaini RC. J. Appl. Phys. 1971; 42: 4883.

2. Cros AJ. J. Electron Spectrosc. Relat. Phenom. 1992; 59: 1.

3. Bart F, Guittet MJ, Thromat N, Gautier M, Duraud JP. J. Electron Spectrosc. Relat. Phenom. 1994; 69: 245.

4. Barr TL. Modern ESCA: the Principles and Practice of X-Ray Photoelectron Spectroscopy. CRC press: Boca Raton, 1994.

5. Verecke G, Rouxhet PG. Surf. Interface Anal. 1998; 26: 490.

6. Cazaux J. J. Electron Spectrosc. Relat. Phenom. 1999; 105: 155.

7. Cazaux J. J. Electron Spectrosc. Relat. Phenom. 2000; 113: 15.

8. Thomas III JH, Bryson III, CE, Pampalone TR. J. Vac. Sci. Technol. B 1988; 6: 1097 .

9. Lau WM. J. Appl. Phys. 1989; 65: 2047.

10. Lau WM. Appl. Phys. Lett. 1989; 54: 338

11. Lau WM. J. Appl. Phys. 1990; 67: 1504.

12. Lau WM, Jin S, Wu XW, Ingrey S. J. Vac. Sci. Technol. B 1990; 8: 848.

13. Lau W, Wu XW. Surf. Sci. 1991; 245: 345.

14. Chan RWM, Kwok RWM, Lau WM. J. Appl. Phys. 1996; 79: 3635.

15. Chan RWM, Kwok RWM, Lau WM, Yan H, Wong SP. J. Vac. Sci. Technol. A 1997; 15: 2787.

16. Shabtai K, Rubinstein I, Cohen SR, Cohen H. J. Am. Chem. Soc. 2000; 122: 4959.

17. Doron-Mor I, Hatzor A, Vaskevich A, van der Boom-Moav T, Shanzer A, Rubinstein I, Cohen H. Nature 2000; 406: 382.

18. Ulgut B, Suzer S. J. Phys. Chem. B 2003; 107: 2939.

19. Clarke RA, Tapping RL, Hopper MA, Young Y. J. Electrochem. Soc. 1975 ; 122: 1348.

20. Hollinger G, Jugnet Y, Pertosa P, Duc TM. Chem. Phys. Lett. 1975; 36: 441.

21. Grunthaner FJ, Grunthaner PJ, Vasquez RP, Lewis BF, Maserjian J, Madhukar A. Phys. Rev. Lett. 1979; 43: 1683. 
22. Grunthaner FJ, Grunthaner PJ, Vasquez RP, Lewis BF, Maserjian J, Madhukar A. J. Vac. Sci. Technol. 1979; 16: 1443.

23. Ishizaka A, Iwata S, Kamigaki Y. Surf. Sci. 1979; 84: 355.

24. Hollinger G. Appl. Surf. Sci. 1981; 8: 318.

25. Hollinger G, Himpsel JF. Appl. Phys. Lett. 1983; 44: 93.

26. Wagner CD, Joshi A, Gulbrandsen L, Deal BE. J. Vac. Sci. Technol. B 1984; 2: 107.

27. Finster J, Schulze D, Bechstedt F, Meisel A. Surf. Sci. 1985; 152/153: 1063.

28. Iqbal A, Bates Jr CW, Allen JW. Appl. Phys. Lett. 1985; 47: 93.

29. Grunthaner FJ, Grunthaner PJ. Mater. Sci. Rep. 1986; 1: 65.

30. Iwata S, Ishizaka A. J. Appl. Phys. 1996; 79: 6653.

31. Zhang KZ, Greeley JN, Banaszak Holl MM, McFeely FR. J. Appl. Phys. 1997; 82: 2298.

32. Zhang KZ, Banaszak Holl MM, McFeely FR. J. Phys. Chem. B 1998; 102: 3930.

33. Kobayashi H, Kubota T, Kawa H, Nakato Y, Nishiyama N. Appl. Phys. Lett. 198; 73: 933.

34. Browning R, Sobolewski MA, Helms CR. Phys. Rev. B 1988; 38: 13407.

35. Pasquarello A, Hybertson MS, Car R. Phys. Rev. B 1996; 53: 10942.
36. Sambe H, Ramaker DE. J. Vac. Sci. Technol. A 1992; 10: 2291.

37. Wu Y, Garfunkel E, Madey TE. J. Vac. Sci. Technol. A 1996; 14: 2554.

38. Reiche R, Yubera F, Espinos JP, Gonzalez-Elippe AR. Surf. Sci. 2000; 457: 199.

39. Suzer S, Sayan S, Banaszak Holl MM, Garfunkel E, Hussain Z, Hamdan NM. J. Vac. Sci. Technol. A 2003; 21: 106.

40. Kingon AI, Maria JP, Streuffer SK. Nature (London) 2000; 406: 1032.

41. Dickinson T, Povey AF, Sherwood PMA. J. Electron Spectrosc. Relat. Phenom. 1973; 2: 441.

42. Johansson G, Hedman J, Berndtsson A, Klasson M, Nilsson R. J. Electron Spectrosc. Relat. Phenom. 1973; 2: 295.

43. Howercraft NJ, Sherwood PMA. Surf. Interface Anal. 2000; 29: 232.

44. Karadas F, Ertas G, Suzer S. J. Phys. Chem. B 2004; 108: 1515.

45. Mitchell DF, Clark KB, Bardwell JA, Lennard WN, Massoumi GR, Mitchell IV. Surf. Interface Anal. 1994; 2: 44.

46. Wagner CD, Joshi A. J. Electron Spectrosc. Relat. Phenom. 1988; 47: 283.

47. Callister Jr WD. Materials Science and Engineering: an Introduction (2nd edn). John Wiley: New York, 1991 